\title{
Multi-function oxidase activity of CYP102A1 (P450BM3) in the oxidation of quinolines and tetrahydroquinolines
}

\author{
Yushu Li, ${ }^{[a]}$ and Luet L. Wong ${ }^{*[a, b]}$
}

\begin{abstract}
Tetrahydroquinoline, quinoline and dihydroquinolinone are common core motifs in drug molecules. Screening of a 48-variant library of the cytochrome P450 enzyme CYP102A1 (P450BM3) followed by targeted mutagenesis based on mutation-selectivity correlations from initial hits, has enabled the hydroxylation of substituted tetrahydroquinolines, quinolines and 3,4-dihydro-2quinolinones at most positions around the two rings in good to high yields at synthetically relevant scales $(1.5 \mathrm{~g} / \mathrm{L} /$ day). Other oxidase activities such as $\mathrm{C}-\mathrm{C}$ bond desaturation, aromatisation and $\mathrm{C}-\mathrm{C}$ bond formation were also observed. The enzyme variants, with mutations at the key active site residues S72, A82, F87, 1263, E267, A328 and A330, provide direct and sustainable routes to oxyfunctionalised derivatives of these building block molecules for synthesis and drug discovery.
\end{abstract}

Tetrahydroquinoline (THQ), quinoline and dihydroquinolinone are ubiquitous core motifs in natural products with important medicinal properties, e.g. alkaloids such as quinine, camptothecin and integriquinolone ${ }^{[1]}$ and in synthetic drugs with varied pharmacological activities including anti-viral, anti-microbial, and anti-tumour compounds. A variety of routes have been developed for the synthesis of compounds with these core motifs for use as building blocks for generating biologically active compounds. Strategies for accessing THQ derivatives include (a) reduction of the heterocyclic ring in the corresponding quinoline derivative, (b) construction of the heterocyclic ring by reactions that form one, two, and three $\mathrm{C}-\mathrm{C}$ bonds, and (c) heterocyclic ring contraction and expansion. ${ }^{[2]}$ Direct functionalisation of the heterocyclic core is a less common strategy due to the modest product selectivity and often more forcing conditions with transition-metal catalysts.

In contrast to chemical systems, enzymatic $\mathrm{C}-\mathrm{H}$ bond activation could provide sustainable and more selective routes for direct functionalisation. CYP102A1 (P450Вм3) from Bacillus megaterium, ${ }^{[3]}$ is a good candidate system on account of its catalytic self-sufficiency, ${ }^{[4]}$ high-level expression in $E$. coli and the excellent scalability of its reactions. ${ }^{[5]}$ The enzyme has been extensively engineered for $\mathrm{C}-\mathrm{H}$ activation of unnatural substrates for applications in synthesis. ${ }^{[6]}$ Rational design, ${ }^{[7]}$ random mutagenesis, ${ }^{[7 \mathrm{~d}, 8]}$ site-saturation mutagenesis and combinatorial active-site saturation test (CAST $)^{[9]}$ have been applied with great success. Another approach is to screen a library of variants for

[a] Y. Li and Dr L.L. Wong

Department of Chemistry, University of Oxford, Inorganic Chemistry Laboratory, South Parks Road, Oxford OX1 3QR, UK E-mail: luet.wong@chem.ox.ac.uk

[b] Oxford Suzhou Centre for Advanced Research, Ruo Shui Road, Suzhou Industrial Park, Jiangsu, 215123, P.R. China

Supporting information for this article is given via a link at the end of the document. initial hits followed by iterative site saturation mutagenesis. ${ }^{[10]}$ Smaller libraries generated from 4-5 mutations at two active site residues have shown high product selectivity for some substrates. ${ }^{[11]}$ We have adopted a similar approach based on CYP102A1 variants found to have increased activity for unnatural substrate oxidation as a result of the heme iron-axial water interaction being weakened by a number of mechanisms. ${ }^{[12]}$ Further mutations were introduced at two to four active site residues (S72, A74, V78, F81, A82, F87, A184, I263, E267, A328, $\mathrm{P} 329$ and $\mathrm{A} 330$ ) in these base variants to afford a library of $\sim 100$ enzymes with diverse substrate pocket topologies. Screenings have shown this library to be capable of $\mathrm{C}-\mathrm{H}$ bond oxyfunctionalisation of different classes of organic compounds. ${ }^{[13]} \mathrm{We}$ report here the oxidation of THQs and quinolines by CYP102A1 variants with the aim to functionalise these building-block molecules selectively at as many positions as possible and thus provide synthetic handles to compounds with biological activity. In addition to $\mathrm{C}-\mathrm{H}$ bond oxidation, we found that CYP102A1 displayed other oxidase activities including desaturation, ${ }^{[14]}$ aromatisation, ${ }^{[15]}$ and $\mathrm{C}-\mathrm{C}$ bond formation reactions.

Screening scale reactions for an initial library of 48 variants [Tables S1 \& S2 in Supporting Information (SI)] were carried out in 24-well plates at $25^{\circ} \mathrm{C}$, shaking at $120 \mathrm{rpm}$. The $1 \mathrm{~mL}$ reactions in $200 \mathrm{mM}$ phosphate buffer (pH 8.4) contained $1 \mu \mathrm{M}$ CYP102A1 enzyme, $40 \mu \mathrm{M} \mathrm{NADP}^{+}$and $2 \mathrm{mM}$ substrate. Glucose and glucose dehydrogenase were used to recycle the NADPH cofactor. Organics were extracted with ethyl acetate and analysed by gas chromatography. Products were isolated from preparative scale reactions $(20-100 \mathrm{mg})$ by silica gel chromatography and characterised by NMR and MS data. The variant library oxidised 1 to a mixture of products (Fig. 1), including 6-hydroxy-THQ, 2, the aromatisation product quinoline, 3, 3,4-dihydro-2-quinolinone, 5, and the dimers 4, 10 and 11 (See Supporting Information). On prolonged reaction, the THQ derivative 2 was fully converted by most of the variants to the aromatised product, 6-quinolinol, 6 .

Mechanistically, 2 is formed via the $\mathrm{NIH}$ shift pathway whereby the initially formed 5,6-arene oxide undergoes ringopening to form the $\mathrm{C} 5$ carbocation preferentially because of stabilisation by the nitrogen lone pair (Scheme 1). Aromatisation of 1 and 2 is likely to be initiated by hydroxylation at $C 2$, the activated $\alpha$-position to the amine nitrogen. The carbinolamine $\mathbf{A}$ loses $\mathrm{OH}^{-}$to give the iminium species which is in equilibrium with the enamine tautomer, the $\mathrm{C} 4-\mathrm{H}$ bond of which is highly activated to hydrogen atom abstraction by Compound I to generate the stabilised allylic-benzylic radical. Aromatisation could occur by $\mathrm{H}$ atom abstraction from the enamine $\mathrm{NH}$ or spontaneous elimination of water from the enamine alcohol formed by radical rebound. The enamine can also undergo nucleophilic attack on its iminium tautomer to form the dimeric iminium species $\mathbf{B}$; under the reaction conditions, the iminium/enamine half of the dimer is 
aromatised to give 4. This 2,3'-THQ-quinoline dimer is hydroxylated at $\mathrm{C} 4$ of the THQ moiety to give 10 which is aromatised to the 2,3'-quinoline-quinoline dimer 11, most likely via an unobserved enamine-alcohol intermediate.

When 5 was screened with the library, we observed hydroxylation at the $\alpha$-position to give 12, desaturation of the $\mathrm{C} \alpha-$ $\mathrm{C} \beta$ bond to form 13, benzylic oxidation to give 14, and formation of the 6-phenol 15 and 8-phenol 16 (Fig. 1). The greater product diversity for $\mathbf{5}$ compared to 1 suggested that the $\mathrm{NH}$ group in THQ might be involved in restricting substrate binding within the active site. Therefore, the $\mathrm{N}$-Boc and $\mathrm{N}$-acyl derivatives of THQ (17 and 20) were tested with the library. We only observed the $C 4$ hydroxylation products $\mathbf{1 8}$ and $\mathbf{2 1}$. On prolonged incubation, the ketones 19 and 22 from further oxidation of these benzylic alcohols were obtained in quantitative yield (Fig. 1, Tables 1, S11 \& S12). Quinoline (3) was also a substrate for the variants, being oxidised to 3-quinolinol, 7, and a stable 5,6-arene oxide, 8. Acidcatalysed arene oxide ring-opening of $\mathbf{8}$ gave 5-quniolinol, $\mathbf{9}$.

Within the screening library, 29 of 48 variants gave $>50 \%$ conversion of 1 while the WT showed negligible activity. Of the products, the variant $\mathrm{RP} / \mathrm{H} 171 \mathrm{~L} / \mathrm{L} 263 \mathrm{G}(\mathrm{RP}=\mathrm{R} 47 \mathrm{~L} / \mathrm{Y} 51 \mathrm{~F} / \mathrm{I401 \textrm {P }})$ gave the highest proportion of the 6-phenol, 2 (54\%, TON $=1080$, Fig. 1, Tables $1 \&$ S5), which was then fully converted to the aromatised product 6 at longer reaction times. Unexpectedly, this variant, and some others (Tables S5 \& S6), did not show any further oxidation of $\mathbf{2}$ until $\mathbf{1}$ had been fully consumed. When purified $\mathbf{2}$ was used as substrate these variants fully converted it to 6 with $100 \%$ selectivity $($ TON $=2,000)$. The variant

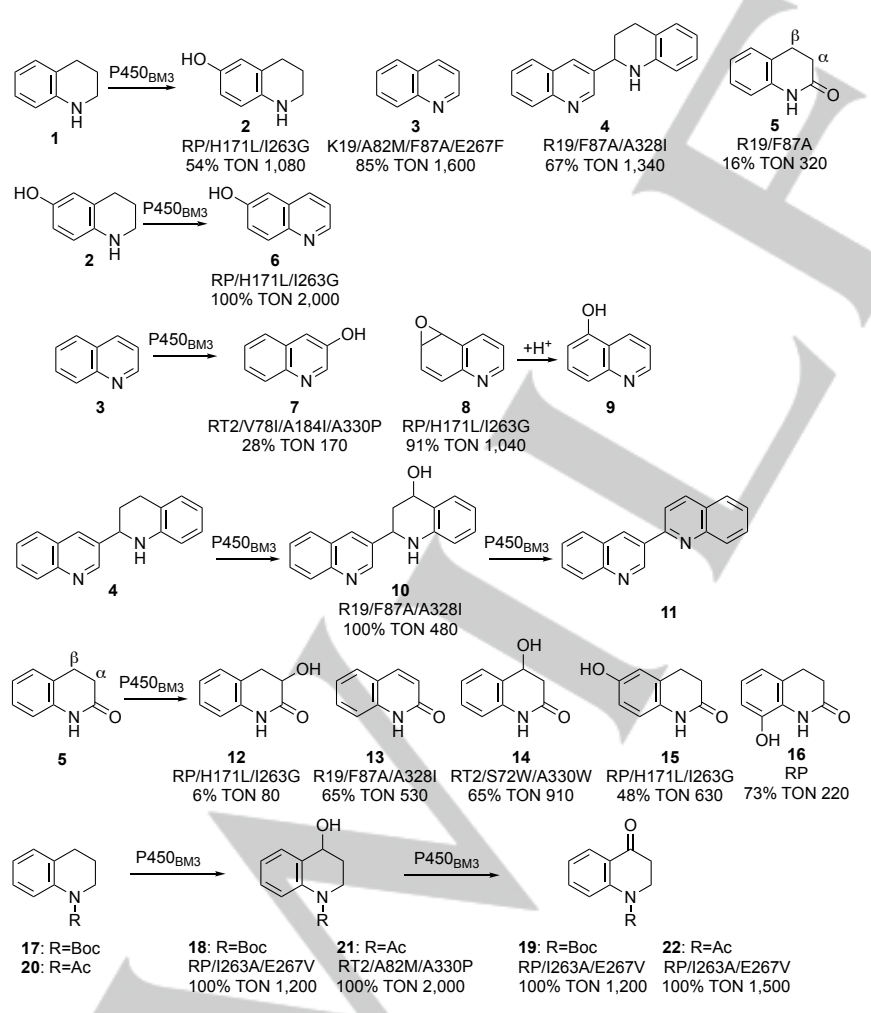

Figure 1. Products from the CYP102A1-catalysed oxidation of 1,2,3,4tetrahydroquinoline $(T H Q, 1)$, showing the most selective variant in the screening library, the proportion of each product and the turnover number (TON).

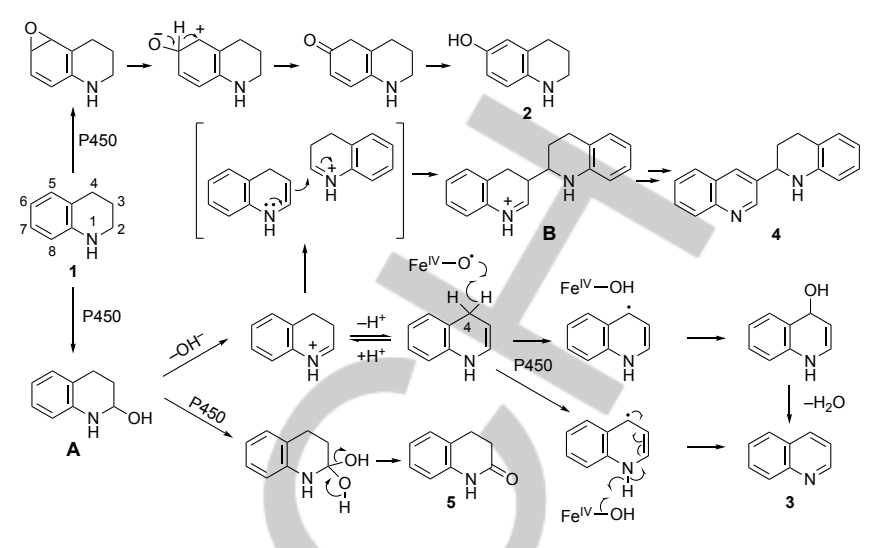

Scheme 1. The proposed mechanistic pathways for the oxidation of $1,2,3,4-$ tetrahydroquinoline $(\mathrm{THQ}, 1)$ by CYP102A1.

$\mathrm{K} 19 / \mathrm{A} 82 \mathrm{M} / \mathrm{F} 87 \mathrm{~A} / \mathrm{E} 267 \mathrm{~F}$ gave $85 \%$ of the aromatisation product 3 ( $\mathrm{TON}=1,600,94 \%$ conversion, $\mathrm{K} 19=\mathrm{H} 171 \mathrm{~L} / \mathrm{Q} 307 \mathrm{H} / \mathrm{N} 319 \mathrm{Y})$, whereas R19/F87A/A328I converted 1 to $67 \%$ of 4 (TON = 1,340, $100 \%$ conversion). The variant R19/F87A gave the highest percentage $(16 \%$, TON $=320)$ of 3,4-dihydro-2-quinolinone, $\mathbf{5}$. For quinoline (3), RT2/V78I/A184I/A330P gave $28 \%$ of $3-$ quinolinol, $7(\mathrm{TON}=170)$, and RP/H171L/I263G gave $91 \%$ of the $5,6$-oxide, 8 ( $57 \%$ conversion, TON $=1,040)$. With $\mathbf{5}$, the 3 -alcohol 12 was a minor product, the RP/H171L/I263G giving $6 \%$ (TON = 80, Table S10); the 6-phenol 15 was the major product for this variant $(48 \%, T O N=630)$. The RP variant gave the highest proportion of 8-phenol $16(73 \%$, TON $=220)$. The R19/F87A/A328I formed 65\% (TON $=530)$ of the aromatised product 2-quinolinol, 13, and RT2/S72W/A330W gave $65 \%$ of the C4-hydroxylation product $14($ TON $=910)$.

We then sought to improve product selectivity by comparing the results for different mutation combinations. The data for $\mathrm{K} 19$, K19/F87A, K19/A328I and R19/F87A/A328I indicated that the native residue $\mathrm{F} 87$ disfavoured $\mathrm{C} 2$ oxidation and gave more C5,C6 oxidation, likewise for the bulky substitution A328I. The F87A and F87V mutations promoted C2 oxidation, leading to aromatisation and formation of the lactam 5 and dimers. The series $\mathrm{RP}, \mathrm{RP} / \mathrm{H} 171 \mathrm{~L}$ and $\mathrm{RP} / \mathrm{H} 171 \mathrm{~L} / \mathrm{I} 263 \mathrm{G}$ revealed that the I263G mutation promoted C5,C6 oxidation. Therefore, the I263G and I263A mutations were combined with A328V, A328L, A328I and $A 328 F$. These four A328 mutations were also combined with F87A in the R19/FA variant. From this new set of variants (Table S3), the R19/I263G showed $100 \%$ conversion of 1 to $80 \%$ of 2 (TON = 1,600) compared to 54\% for RP/H171L/I263G (Tables 1 \& S6). This was improved to $87 \%$ with the R19/I263G/A328L (TON $=1,740,100 \%$ conversion). The change from $\mathrm{A} 328 \mathrm{I}$ to A328L led to increased formation of the THQ-quinoline dimer 4 for the R19/F87A/A328L variant (78\%, up from $67 \%)$. The new variants also showed increased selectivity for the oxidation of 3,4dihydro-2-quinolinone 5, with R19/I263G giving an albeit low $12 \%$ of the 3-alcohol 12 (TON = 170), and the R19/I263G/A328L forming $100 \%$ of the 6 -phenol 15 (95\% conversion).

Next, we explored the effect of substituents on THQ oxidation by both the initial library and $2^{\text {nd }}$-generation variants with 2-methyl-tetrahydroquinoline (2MTHQ, 23) and 8-methyltetrahydroquinoline $(8 \mathrm{MTHQ}, 31)$. Formation of the 6-hydroxy 
derivatives was unaffected (Fig. 2). Gratifyingly, as with THQ, the $2^{\text {nd }}$-generation variant $\mathrm{R} 19 / \mathrm{I} 263 \mathrm{G} / \mathrm{A} 328 \mathrm{~L}$ was also the most selective for both, with $100 \%$ selectivity at $93 \%$ conversion for $\mathbf{2 4}$ (TON $=1,860$, Table 1$)$ and $84 \%$ for $32(\mathrm{TON}=1,680)$. On prolonged reaction both $\mathbf{2 4}$ and $\mathbf{3 2}$ were aromatised with total conversion to the corresponding methylquinolinols 26 and $\mathbf{3 6}$. As observed with 2, there was no further oxidation of $\mathbf{2 4}$ and $\mathbf{3 2}$ with some variants until $\mathbf{2 3}$ and $\mathbf{3 1}$ had been fully consumed. F87based variants showed the highest aromatisation activity, at $66 \%$ for the formation of 2-methylquinoline $(25$, TON $=420)$ and $84 \%$ for 8-methylquinoline $(33$, TON $=1,010)$. It appears that aromatisation of THQs to the quinoline analogues is a general activity of CYP102A1 variants, which offers an unexpected route for interconversion between these two classes of compounds by hydrogenation/aromatisation. The K19/A82M/F87A variant gave the most $(77 \%$, TON $=1,540)$ of the dimer 34 . No dimer was observed with $\mathbf{2 3}$, presumably because of steric hindrance by the 2-methyl substituent to nucleophilic attack by the enamine on the iminium species. F87A and F87V-based variants gave higher proportions of the dihydro-2-quinolinone 35 from $8 \mathrm{MTHQ}$ (GVQ/A264G 27\%, TON = 280).

The methyl substituent had greater effect on quinoline oxidation. The 3-quinolinol derivatives were formed with moderate selectivity: $56 \%$ (TON $=290$ ) of 2-methyl-3-quinolinol, 27 , by the RP variant, and $38 \%$ (TON $=280$ ) of 8-methyl-3-quinolinol, 37 , by R19/I263A/A328L. The 5,6-oxide 29 from the oxidation of 25 was stable under turnover conditions and could be isolated; the $\mathrm{R} 19 / \mathrm{I} 263 \mathrm{G}$ variant gave 29 with $81 \%$ selectivity (TON $=1,150)$. Treatment of $\mathbf{2 9}$ with acid gave a mixture of 2-methyl-5-qunolinol $(30,62 \%)$ and 2-methyl-6-quinolinol (26, 38\%). Here, stabilisation of the C5 carbocation from arene oxide ring opening by the 2methyl substituent altered the selectivity compared to

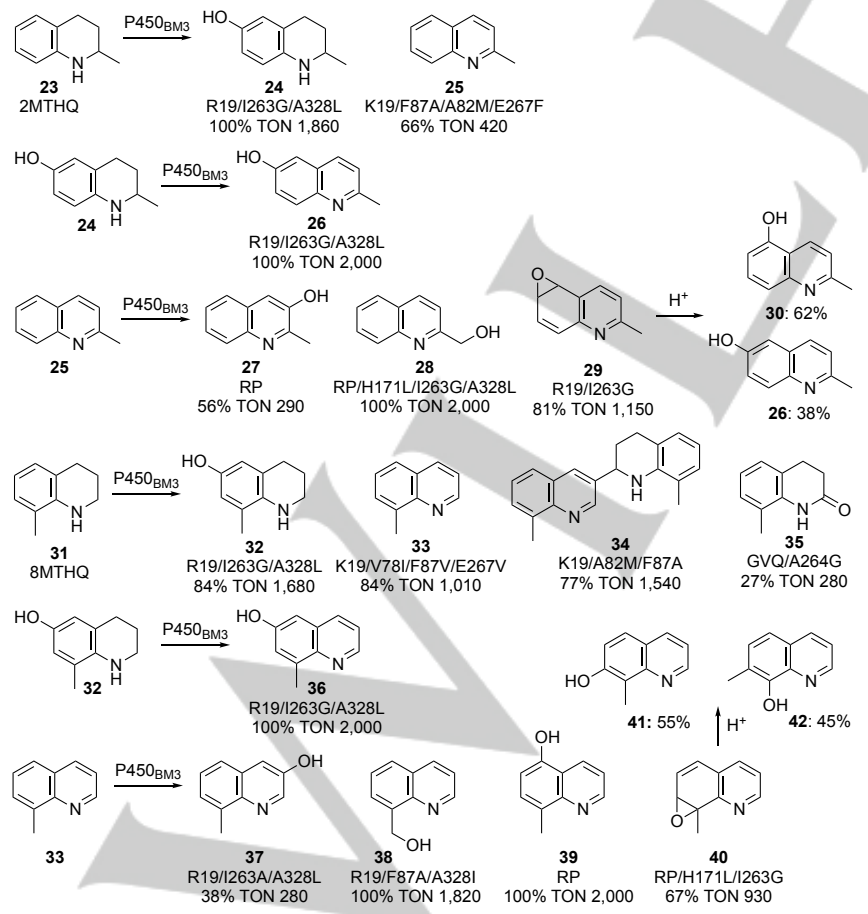

Figure 2. The reaction scheme of $P 450_{\mathrm{BM}}$ oxidation of $2 \mathrm{MTHQ}$ and $8 \mathrm{MTHQ}$.
Table 1. Activity and selectivity for the oxidation of tetrahydroquinolines and quinolines by CYP102A1 variants. * denotes a second-generation variant.

\begin{tabular}{|c|c|c|c|}
\hline Product & CYP102A1 Variant & Selectivity & TON \\
\hline 2 & $\mathrm{R} 19 / 1263 \mathrm{G} / \mathrm{A} 328 \mathrm{~L}^{*}$ & $87 \%$ & 1,740 \\
\hline 3 & K19/A82M/F87A/E267F & $85 \%$ & 1,600 \\
\hline 4 & R19/F87A/A328L* & $78 \%$ & 1,510 \\
\hline 5 & $\mathrm{R} 19 / \mathrm{F} 87 \mathrm{~A} / \mathrm{I} 263 \mathrm{G}^{*}$ & $20 \%$ & 400 \\
\hline 6 & $\mathrm{R} 19 / 1263 \mathrm{G} / \mathrm{A} 328 \mathrm{~L}^{*}$ & $100 \%$ & 2,000 \\
\hline 7 & $\mathrm{RT2/V78I/A184I/A330P}$ & $28 \%$ & 170 \\
\hline 8 & $\mathrm{RP} / \mathrm{H} 171 \mathrm{~L} / \mathrm{I} 263 \mathrm{G}$ & $91 \%$ & 1,040 \\
\hline 10 & R19/F87A/A328L* & $100 \%$ & 1,150 \\
\hline 12 & $\mathrm{R} 19 / \mathrm{I} 263 \mathrm{G}^{*}$ & $12 \%$ & 170 \\
\hline 13 & R19/F87A/A328I & $65 \%$ & 530 \\
\hline \multirow[t]{2}{*}{14} & $\mathrm{RT} 2 / \mathrm{S} 72 \mathrm{~W} / \mathrm{A} 330 \mathrm{~W}$ & $65 \%$ & 910 \\
\hline & A74G/F87L/L188Q/I263G/A328G* & $80 \%$ & 380 \\
\hline 15 & $\mathrm{R} 19 / 1263 \mathrm{G} / \mathrm{A} 328 \mathrm{~L}^{*}$ & $100 \%$ & 1,900 \\
\hline 16 & $\mathrm{RT} 2 / \mathrm{S} 72 \mathrm{H} / \mathrm{A} 330 \mathrm{~W}^{*}$ & $51 \%$ & 730 \\
\hline 18 & RP/I263A/E267V & $100 \%$ & 1,200 \\
\hline 19 & $\mathrm{RP} / \mathrm{I} 263 \mathrm{~A} / \mathrm{E} 267 \mathrm{~V}$ & $100 \%$ & 1,200 \\
\hline 21 & $\mathrm{RT} 2 / \mathrm{A} 82 \mathrm{M} / \mathrm{A} 330 \mathrm{P}$ & $100 \%$ & 2,000 \\
\hline 22 & RP/I263A/E267V & $100 \%$ & 1,500 \\
\hline 24 & $\mathrm{R} 19 / 1263 \mathrm{G} / \mathrm{A} 328 \mathrm{~L}^{*}$ & $100 \%$ & 1,860 \\
\hline 25 & K19/A82M/F87A/E267F & $66 \%$ & 420 \\
\hline 26 & $\mathrm{R} 19 / \mathrm{I263G/A328L^{* }}$ & $100 \%$ & 2,000 \\
\hline 27 & $\mathrm{RP}$ & $56 \%$ & 290 \\
\hline 28 & RP/H171L/I263G/A328L* & $100 \%$ & 2,000 \\
\hline 29 & $\mathrm{R} 19 / \mathrm{I} 263 \mathrm{G}^{*}$ & $81 \%$ & 1,150 \\
\hline 32 & R19/I263G/A328L* & $84 \%$ & 1,680 \\
\hline 33 & K19/V78I/F87V/E267V* & $84 \%$ & 1,010 \\
\hline 34 & K19/A82M/F87A & $77 \%$ & 1,540 \\
\hline 35 & GVQ/A264G* & $27 \%$ & 280 \\
\hline 36 & $\mathrm{R} 19 / \mathrm{I263G/A328L^{* }}$ & $100 \%$ & 2,000 \\
\hline 37 & $\mathrm{R} 19 / \mathrm{I263A} / \mathrm{A} 328 \mathrm{~L}^{*}$ & $38 \%$ & 280 \\
\hline 38 & R19/F87A/A328I & $100 \%$ & 1,820 \\
\hline 39 & $\mathrm{RP}$ & $100 \%$ & 2,000 \\
\hline 40 & $\mathrm{RP} / \mathrm{H} 171 \mathrm{~L} / \mathrm{I} 263 \mathrm{G}$ & $67 \%$ & 930 \\
\hline
\end{tabular}

unsubstituted quinoline. The 5,6-oxide of $\mathbf{3 3}$ was not observed, with the RP variant forming 8-methyl-5-quinolinol (39) with $100 \%$ selectivity $(T O N=2,000)$. The 8 -methyl group likely played a role in this outcome by stabilising a $\mathrm{C} 6$ carbocation upon ring opening of the 5,6-arene oxide. Interestingly, the RP/H171L//I263G variant oxidised $\mathbf{3 3}$ to the 7,8 -oxide $\mathbf{4 0}$ with $67 \%$ selectivity (TON $=930$ ). On treatment with acid, 40 gave 8-methyl-7-quinolinol, 41 (55\%), via an $\mathrm{NIH}$ shift after arene oxide ring opening to form the $\mathrm{C} 8$ carbocation but also the regioisomer 7-methyl-8-quinolinol, 42 (45\%), from an NIH shift of the methyl group in a C7-cation intermediate. Benzylic oxidation of both methylquinolines $\mathbf{2 5}$ and 33 was observed across the variant library with up to $100 \%$ selectivity for the benzylic alcohols $28(\mathrm{RP} / \mathrm{H} 171 \mathrm{~L} / \mathrm{I} 263 \mathrm{G} / \mathrm{A} 328 \mathrm{~L}$, TON $=2,000)$ and $38(\mathrm{R} 19 / \mathrm{F} 87 \mathrm{~A} / \mathrm{A} 328 \mathrm{I}$, TON = 1,820).

With the $2^{\text {nd }}$-generation variants included, less than 80 CYP102A1 variants in total were screened and yet a good fraction of the possible oxidation sites in the tested substrates, including aromatisation of THQs to quinolines, were accessible with good to high selectivity and TON $(>1,000)$. Combinations of mutations 
at F87, A328 and I263 were particularly effective, with mutations at S72, A82, E267 and A330 also playing a role. Interestingly, the variant library catalysed the benzylic (C4) oxidation of the $\mathrm{N}-\mathrm{Ac}$ and $N$-Boc derivatives of THQ to the alcohol and then the ketone, and near-total selectivity for benzylic oxidation of methylquinolines was observed. Therefore, the combinations of mutations in this collection of variants demonstrated good control over the regioselectivity of attack on the two rings as well as the partitioning between reaction pathways after initial $\mathrm{H}$-atom abstraction. The exceptions were the absence of C3, C7,C8 and benzylic methyl oxidation of THQs and the low yields of the 3phenols from the quinolines. Further enzyme engineering is required to achieve oxidation at these positions. The biotransformation of $\mathrm{THQ}$ was scalable. For example, the oxidation of 1 by RP/H171L/I263G at $100 \mathrm{~mL}$ scale in shake flasks, without active aeration, agitation or $\mathrm{pH}$ control, afforded $100 \%$ conversion of $>20 \mathrm{mM}$ of 1 with a TON $>10,000$ by sequential addition of $4 \mathrm{mM}$ aliquots of substrate over 2 days $(1.5 \mathrm{~g} / \mathrm{L} /$ day $)$, with a total product yield of $160 \mathrm{mg}(60 \%)$.

In summary, CYP102A1 shows multi-function oxidase activity in the oxidation of quinolines, tetrahydroquinolines and 3,4-dihydro-2-quinolinone. Substituents on both rings of these core motifs were well tolerated by the CYP102A 1 variants, and there were good indications of the residues and mutations to be targeted for the selective oxy-functionalisation of these important building block compounds at specific positions.

\section{Experimental Section}

Experimental details are shown in Supporting Information.

\section{Acknowledgements}

YL is supported by a Vice Chancellor's Scholarship from Oxford University.

Keywords: $\mathrm{P} 450 \cdot$ Protein engineering $\bullet \mathrm{C}-\mathrm{H}$ activation $•$ Nitrogen heterocyclic compounds $\bullet$ alkaloids

\section{References}

[1] a) A. A. L. Gunatilaka, in The Alkaloids: Chemistry and Biology, Vol. 52 (Ed.: G. A. Cordell), Academic Press, 1999, pp. 1-101; b) A. M. Patten, D. G. Vassão, M. P. Wolcott, L. B. Davin, N. G. Lewis, in Comprehensive Natural Products II: Chemistry and Biology, Vol. 3 (Eds.: H.-W. Liu, L. Mander), Elsevier, 2010, pp. 1173-1296.

[2] a) A. R. Katritzky, S. Rachwal, B. Rachwal, Tetrahedron 1996, 52, 15031 15070; b) V. Sridharan, P. A. Suryavanshi, J. C. Menendez, Chem. Rev. 2011, 111, 7157-7259.

[3] Y. Miura, A. J. Fulco, J. Biol. Chem. 1974, 249, 1880-1888.

[4] L. O. Narhi, A. J. Fulco, J. Biol. Chem. 1986, 261, 7160-7169.

[5] a) S. Pflug, S. M. Richter, V. B. Urlacher, J. Biotechnol. 2007, 129, 481 488; b) J. Brummund, M. Muller, T. Schmitges, I. Kaluzna, D. Mink, L. Hilterhaus, A. Liese, J. Biotechnol. 2016, 233, 143-150; c) I. Kaluzna, T. Schmitges, H. Straatman, D. van Tegelen, M. Muller, M. Schurmann, D. Mink, Org. Process Res. Dev. 2016, 20, 814-819.

[6] a) C. J. C. Whitehouse, S. G. Bell, L. L. Wong, Chem. Soc. Rev. 2012 41, 1218-1260; b) S. T. Jung, R. Lauchli, F. H. Arnold, Curr. Opin. Biotechnol. 2011, 22, 809-817; c) R. Fasan, ACS Catal. 2012, 2, 647-666; d) C. A. Denard, H. Ren, H. Zhao, Curr. Opin. Chem. Biol. 2015, 25, 5564.

[7] a) W. L. Alworth, Q. W. Xia, H. M. Liu, FASEB J. 1997, 11, 9SS, 190; b) T. W. Ost, C. S. Miles, J. Murdoch, Y. Cheung, G. A. Reid, S. K. Chapman, A. W. Munro, FEBS Lett. 2000, 486, 173-177; c) A. B. Carmichael, L. L.
Wong, FEBS J. 2001, 268, 3117-3125; d) Q. S. Li, J. Ogawa, R. D. Schmid, S. Shimizu, Appl. Environ. Microbiol. 2001, 67, 5735-5739; e) W. C. Huang, A. C. Westlake, J. D. Marechal, M. G. Joyce, P. C. Moody, G. C. Roberts, J. Mol. Biol. 2007, 373, 633-651; f) R. J. Sowden, S. Yasmin, N. H. Rees, S. G. Bell, L. L. Wong, Org. Biomol. Chem. 2005, 3, 57-64; g) R. J. Branco, A. Seifert, M. Budde, V. B. Urlacher, M. J. Ramos, J. Pleiss, Proteins 2008, 73, 597-607; h) A. M. Sawayama, M. M. Chen, P. Kulanthaivel, M. S. Kuo, H. Hemmerle, F. H. Arnold, Chem. Eur. J. 2009, 15, 11723-11729; i) A. Seifert, J. Pleiss, Proteins 2009, 74, 1028-1035.

[8] a) Q. S. Li, U. Schwaneberg, P. Fischer, R. D. Schmid, Chem. Eur. J. 2000, 6, 1531-1536; b) E. T. Farinas, U. Schwaneberg, A. Glieder, F. H. Arnold, Adv. Synth. Catal. 2001, 343, 601-606; c) A. Glieder, E. T. Farinas, F. H. Arnold, Nat. Biotechnol. 2002, 20, 1135-1139; d) M. W. Peters, P. Meinhold, A. Glieder, F. H. Arnold, J. Am. Chem. Soc. 2003, 125, 13442$13450 ;$ e) B. M. Lussenburg, L. C. Babel, N. P. Vermeulen, J. N. Commandeur, Anal. Biochem. 2005, 341, 148-155; f) B. M. van VugtLussenburg, E. Stjernschantz, J. Lastdrager, C. Oostenbrink, N. P. Vermeulen, J. N. Commandeur, J. Med. Chem. 2007, 50, 455-461; g) J. C. Lewis, F. H. Arnold, Chimia 2009, 63, 309-312.

[9] a) S. Kille, F. E. Zilly, J. P. Acevedo, M. T. Reetz, Nat. Chem. 2011, 3, 738-743; b) C. G. Acevedo-Rocha, C. G. Gamble, R. Lonsdale, A. T. Li, N. Nett, S. Hoebenreich, J. B. Lingnau, C. Wirtz, C. Fares, H. Hinrichs, A. Deege, A. J. Mulholland, Y. Nov, D. Leys, K. J. McLean, A. W. Munro, M. T. Reetz, ACS Catal. 2018, 8, 3395-3410.

[10] a) K. Zhang, B. M. Shafer, M. D. Demars, 2nd, H. A. Stern, R. Fasan, J. Am. Chem. Soc. 2012, 134, 18695-18704; b) A. Rentmeister, F. H. Arnold, R. Fasan, Nat. Chem. Biol. 2009, 5, 26-28; c) K. Zhang, S. El Damaty, R. Fasan, J. Am. Chem. Soc. 2011, 133, 3242-3245; d) J. N. Kolev, K. M. O'Dwyer, C. T. Jordan, R. Fasan, ACS Chem. Biol. 2014, 9, 164-173.

[11] a) A. Seifert, S. Vomund, K. Grohmann, S. Kriening, V. B. Urlacher, S. Laschat, J. Pleiss, Chembiochem 2009, 10, 853-861; b) E. Weber, A. Seifert, M. Antonovici, C. Geinitz, J. Pleiss, V. B. Urlacher, Chem. Commun. 2011, 47, 944-946.

[12] a) C. J. C. Whitehouse, S. G. Bell, H. G. Tufton, R. J. Kenny, L. C. Ogilvie, L. L. Wong, Chem. Commun. 2008, 966-968; b) C. J. C. Whitehouse, S. G. Bell, W. Yang, J. A. Yorke, C. F. Blanford, A. J. Strong, E. J. Morse, M. Bartlam, Z. Rao, L. L. Wong, Chembiochem 2009, 10, 1654-1656; c) C. J. C. Whitehouse, W. Yang, J. A. Yorke, B. C. Rowlatt, A. J. Strong, C. F. Blanford, S. G. Bell, M. Bartlam, L. L. Wong, Z. Rao, Chembiochem 2010, 11, 2549-2556; d) C. J. C. Whitehouse, W. Yang, J. A. Yorke, H. G. Tufton, L. C. Ogilvie, S. G. Bell, W. Zhou, M. Bartlam, Z. Rao, L. L. Wong, Dalton Trans. 2011, 40, 10383-10396.

[13] a) X. Ren, J. A. Yorke, E. Taylor, T. Zhang, W. Zhou, L. L. Wong, Chem. Eur. J. 2015, 21, 15039-15047; b) X. K. Ren, J. A. O'Hanlon, M. Morris, J. Robertson, L. L. Wong, ACS Catal. 2016, 6, 6833-6837; c) J. A. O'Hanlon, X. Ren, M. Morris, L. L. Wong, J. Robertson, Org. Biomol. Chem. 2017, $15,8780-8787$.

[14] C. J. C. Whitehouse, S. G. Bell, L. L. Wong, Chem. Eur. J. 2008, 14, 10905-10908.

[15] N. Beyer, J. K. Kulig, M. W. Fraaije, M. A. Hayes, D. B. Janssen, Chembiochem 2018, 19, 326-337. 
WILEY-VCH

\section{Entry for the Table of Contents}

\section{COMMUNICATION}

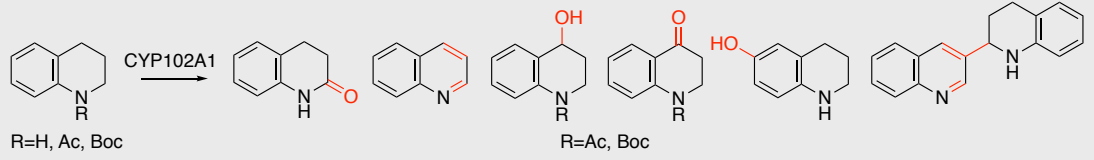

A library of CYP102A1 (P450BM3) variants show desaturation, aromatisation and C$\mathrm{C}$ bond formation in addition to the normal $\mathrm{C}-\mathrm{H}$ bond oxidation activity in the oxidation of tetrahydroquinolines, quinolines and dihydroquinolinones with high selectivity and turnover numbers.
Yushu Li and Luet L. Wong **

Page No. - Page No.

Multi-function oxidase activity of CYP102A1 in the oxidation of quinolines and tetrahydroquinolines 